Journal of

Health, Medicine and Nursing

(JHMN)

\title{
IMPACT OF SELF-EFFICACY THEORY ON IMPROVING ADHERENCE OF OLDER ADULTS PATIENTS WITH GLAUCOMA'S MEDICATION
}

Faiza A. Abou-El-Soud and Helalia Shalabi Mohamed 
Journal of Health, Medicine and Nursing

ISSN 2520-4025 (Online)

Vol.5, Issue 4. No.5, pp 44- 70, 2020

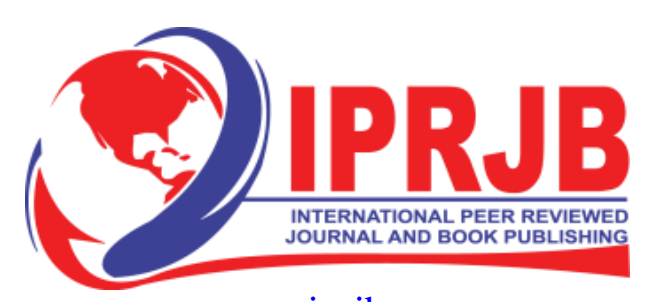

WWw.iprib.org

IMPACT OF SELF-EFFICACY THEORY ON IMPROVING ADHERENCE OF OLDER ADULTS PATIENTS WITH GLAUCOMA'S MEDICATION

\author{
1 *Faiza A. Abou-El-Soud \\ Assistant Professor: Community Health Nursing, College of Nursing, Menoufiya University, \\ Egypt \\ *Corresponding Author's E-mail: soudf@ksau-hs.edu.sa \\ ${ }^{2}$ Helalia Shalabi Mohamed \\ Lecturer: Community Health Nursing, College of Nursing, Cairo \\ University, Egypt
}

Purpose: This study was aimed to measure the impact of self-efficacy theory to improve medication adherence among older adults' patients with glaucoma.

Methodology: A quasi-experimental design was used to investigate the study hypotheses.

Study Sample: A total of 284 older adults with glaucoma were screened to select non-adherent patients with medication. The recruited study sample was (152) who are non-adherent with glaucoma medication divided equally into (76 study group) and (76 control group). Setting: the study was conducted at the outpatient clinics of Ophthalmology at University Hospital, Shebin El-Kom, Egypt. Tools: three tools were used for the purpose of data collection (I) Bio-sociodemographic characteristics questionnaire; (II) Medication Adherence Rating Scale (III) Glaucoma Medication Self-Efficacy Scale.

Findings: The findings revealed that the mean age of the studied sample was $74.86 \pm 4.63$ (nonadherent to medication). Patients age and presence of more than three multiple chronic illnesses with poly-medications are the highest risk factors of adherence to medications (OR $=10.9 ; 95 \%$ CI $6.8-16.32, \mathrm{P}=0.000) ;(\mathrm{OR}=12.6 ; 95 \% \mathrm{CI} 8.2-18.4, \mathrm{P}=0.000)$ and $(\mathrm{OR}=13.2 ; 95 \% \mathrm{CI} 7.4$ $-19.8, \mathrm{P}=0.000)$ respectively. Participants who received the intervention program showed a significant improvement in their self-efficacy in overcoming medication adherence barriers compared to the control group. An improvement of the self-efficacy in their ability in carrying out glaucoma medication correctly compared to the control group was shown by highly statistically significant differences between total mean scores at $(\mathrm{t}=3.426, \mathrm{P}=.001 ; \mathrm{t}=17.174$, $\mathrm{P}=.000 ; \mathrm{t}=18.141, \mathrm{P}=.000)$ respectively. The intervention program of glaucoma medication management had a positive impact on the patients' outcomes compared to the control group. There is a statistically significant difference between patients' feelings and thoughts pre and post-intervention was detected.

Unique contribution to theory, practice and policy: The findings confirm the effectiveness of an intervention/educational program based on self-efficacy theory in terms of improving glaucoma medication adherence among older adults. Glaucoma's medication principles should be discussed at regular intervals based on patients' needs and the barriers they are facing.

Keywords: Self-Efficacy, Medication Adherence, Older Adults, Glaucoma 
Journal of Health, Medicine and Nursing

ISSN 2520-4025 (Online)

Vol.5, Issue 4. No.5, pp 44- 70, 2020

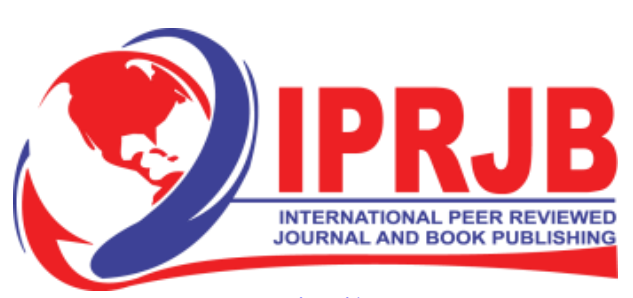

WWW.iprjb.org

those patients contaminated the eye drop bottle by touching it to their eyes. ${ }^{(22)}$ Additionally, other studies showed that $20 \%$ of patients reported that no one had shown how to use their glaucoma medication and around $50 \%$ of the patients discontinue of the glaucoma medication within six months. ${ }^{(23-25)}$

By improving medication adherence through self-efficacy that play a significant role in changing the individual's behavior and cognitive processes which enhance one's confidence in their ability to carrying out a particular task in a successful approach. Non-adherence to medication among elderly patients has a negative impact that may result in the financial burden on the patients and health care systems due to increasing health care cost during re-hospitalization with a high rate of other co-morbidity which leads to delayed recovery and a rise in the mortality rate, hence this theory-based intervention is contributed to reducing burned of cost. ${ }^{(26-29)}$ Therefore, the aim of the study was to measure the impact of self-efficacy theory to improve medication adherence among older adults' patients with glaucoma.

\section{Theoretical Framework}

According to Lopez-Garrido, (2020); Conner, (2010); Bandura's theory, (2001) self-efficacy is one of the key constructs in the social cognitive theory that applied in the current study to improve the self-confidence of the elderly patients for overcoming medication adherence barriers; and increase self-efficacy in carrying the medication correctly and evaluate the outcome expectations. ${ }^{(30-32)}$ In addition, Bandura theory, (2001) elaborated that an individual's behavior is affecting by two factors: firstly, self-efficacy i.e., an individual's feelings and thoughts towards his/ her ability to achieve a specific task or activity which is measuring in the current study through the glaucoma medication self-efficacy scale. ${ }^{(30)}$ In addition, the effort that will spend to carry out the task which is measuring through self-efficacy in carrying out specific tasks subscale, and how long he/she will persist to engage in this task when confronted with barriers which are measuring through self-efficacy in overcoming barriers subscale. ${ }^{(30)}$ Therefore, those scales were reflecting self-efficacy where the elderly participants' confidence in the ability to complete a task or achieve a goal. Secondly, the outcome expectancy i.e., an individual's feelings and thoughts to have good behavior after the effective intervention that improves their selfefficacy which is measuring in the current study through the outcome expectation subscale. ${ }^{(30)}$ According to Lopez-Garrido, (2020); Conner, (2010); Bandura's theory, (2001) stated that the individuals who perceived high self-efficacy, are more active and persistent to accomplish the task versus the individuals who not perceived self-efficacy, are less active, and not able to persistent in accomplishing the task. ${ }^{(30-32)}$

Based on Rdemond, (2010); Bandura, (1977) declared that the development of self-efficacy is gained through four sources of self-efficacy beliefs for sustaining an individual's behavior and performance to medication adherence. These self-efficacy sources are comprised:(1)Enactive e Mastery - i.e., when the individuals accomplished a new task well and succeeded, this experience can build up a high level of self-efficacy and self-confidence, which associated with similar tasks versus the individuals who have a low level of self-efficacy for a certain task, so they avoid this perform a task which prevents them to gain a positive the experience that might build up their self-confidence. (2)Vicarious Experience - i.e., people can develop high selfefficacy by watching other people on the You-tube and other medical resources such as brochure which demonstrate the right technique of eye drop treatment. Observing other people are more 
Journal of Health, Medicine and Nursing

ISSN 2520-4025 (Online)

Vol.5, Issue 4. No.5, pp 44- 70, 2020

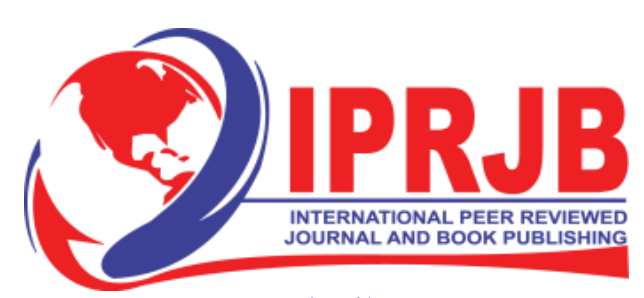

WWW.iprjb.org

likely to influence the individual self-efficacy when they feel that they are similar to the person who is watching; (3)Verbal Persuasion- i.e., self-efficacy is affected by reassurance and support relating to an individual's capability to achieve a new specified task such as adherence to medication; (4)Physiological Arousal - i.e., the individuals who have a positive emotion is producing greater feelings of self-efficacy versus the individuals who have negative emotions that aggravate the feeling of fear or anxiety which can challenge the individual's selfefficacy. ${ }^{(33,34)}$ In addition, self-efficacy has several effects on thought patterns and responses which included: (1) Choices (approach versus avoid) - i.e., individuals who have low selfefficacy can lead them to avoid tasks because they believe this task is more difficult than they are excepted to perform. In the opposite approach, when the individuals have a high self-efficacy level, it leads the individual to have self-competence to complete tasks. ${ }^{(35,36)}$ (2) Motivation individuals who have high self-efficacy are more expected to do efforts to achieve their tasks and continue longer in those efforts than those who have low self-efficacy. In addition, individuals with low self-efficacy can lead them to have certain beliefs that they do not have an effort and helplessness to achieve their tasks successfully. (3) Work performance i.e., self-efficacy is definitely and strongly linked to work-related performance. This association depends on the difficulty of the task i.e., if the required task is complex to carry out, the individual may face low self-confidence to perform this task because it beyond his/her ability to perform compared to if the work-related task is simple, the individual has high self-confidence to perform. This indicates that the health care provider should deliver an accurate description of the tasks such as medication intake which is the essential supporting element for patients' health conditions to succeed in their adherence to medication. ${ }^{(37-38)}$ (4) Thought patterns and responses - when individuals have low self-efficacy that can lead them to believe that the task is harder than they actually are. This often consequences due to weak task planning, as well as exposure to stressors and giving up. In other words, individuals with high self-efficacy have a tendency to act towards the task to control the best plan and accomplish a specific task. ${ }^{(39-41)}$

In other words, Patton, Ryan, Hughes (2020); Vrijens, Antoniou, Burnier, de la Sierra, Volpe (2017); Kardas, Lewek, Matyjaszczyk (2013); Bandura, (2001) who originally proposed the concept of self-efficacy is one of the main influential patients-related factors, and if it is not treated properly and it may lead to deterioration of the patient's health condition or delayed the patient recovery from their chronic illness. ${ }^{(42-44,32)}$ According to Navarra, Gwadz, Bakken, Whittemore, Cleland, Melkus, (2019); Lubloy,(2014) presented that the nurse plays a crucial role in the health care system to link between theory and practices through the application of the selfefficacy theory for changing adherence to medication behavior among older adults' patients with glaucoma which had a greater influence on the effectiveness of treatment. ${ }^{(45,46) .}$

Due to the silent thief of sight, slowly progressive, and irreversible nature of the vision loss that occurs with glaucoma, so the nursing interventions are required to focus upon the early detection and prevention of disease progression of glaucoma. ${ }^{(13-15)}$ The nursing interventions are included the strict control of intraocular pressure by proper instructions about the correct technique for administration of the prescribed anti-glaucoma medication that increases the individual selfconfidence to carrying out this a particular task and how to overcoming medication adherence barriers. Therefore, increasing self-efficacy among older adults' patients with glaucoma which has a positive influence on the patient's behavior and positive health outcomes towards adherence to the medications. ${ }^{(39-41)}$ 
Journal of Health, Medicine and Nursing

ISSN 2520-4025 (Online)

Vol.5, Issue 4. No.5, pp 44- 70, 2020

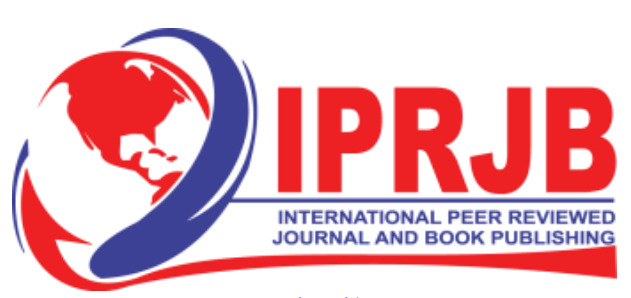

\subsection{METHODOLOGY}

WWW.iprib.org

Research Design: A quasi-experimental design was used to investigate the study hypotheses.

Research Setting: The baseline data was collected at the outpatient clinic of Ophthalmology at University Hospital, Shebin El-Kom, Egypt. Follow-up phases was conducted every four weeks (week $4,8,12$ ) during their regular routine visit at the ophthalmic clinic. The data was collected between the end of May 2018 to the end of October 2019.

Study Sample: A total of 284 older adults suffer from glaucoma, regularly attending Ophthalmology outpatient clinic to receive their medical care was surveyed firstly using the Medication Adherence Rating Scale (MARS) to categorize participates into two groups: an adherent or non-adherent to glaucoma's medications. By using sample size calculator Rao soft, in power analysis of $\alpha 0.05$, power 90 , and medium effect size of 0.2 , and using the correlation test, considering the confidence level $95 \%$ and a confidence interval 5\% was (152). One-hundred fifty-two non-adherent participants were recruited for the purpose of the study after screened two-hundred eighty-four elderly patients with glaucoma. This non-adherent group was divided into two subgroups (study group=76 and control group=76). The researchers quantified the inclusion and exclusion criteria for participants who registered in the study as the flow chart described below in (Figure-2). 
Journal of Health, Medicine and Nursing

ISSN 2520-4025 (Online)

Vol.5, Issue 4. No.5, pp 44- 70, 2020

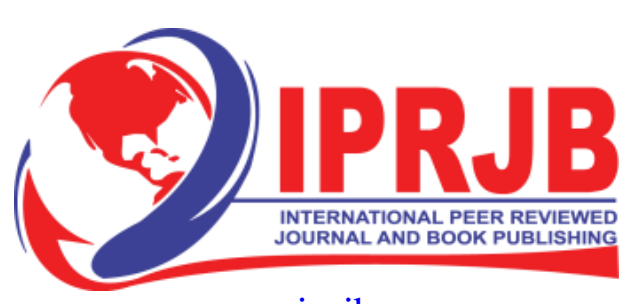

WWW.iprib.org

with a reliability coefficient (0.71) that attested to the internal consistency of the MARS questionnaire. ${ }^{(47)}$

Tool III. Glaucoma Medication Self-Efficacy Scale: This scale was developed by Sleath, et al., 2010. ${ }^{(22)}$ It consists of three dimensions:

(1-III) Self-efficacy in overcoming barriers subscale - which included 21 items to assess the patient's ability to overcoming barriers that might interfere with the use of glaucoma medications. The older adults' patient's response for this glaucoma medication self-efficacy scale was categorized for self-efficacy items into $(0=$ Does not apply; $1=$ not at all confident; $2=$ somewhat confident, $3=$ very confident). The Cronbach alpha value for self-efficacy in overcoming barriers subscale was (0.90), with scores ranged from (0-63).

(2-III) Self-efficacy in carrying out specific task subscale - which included 14 items that assess the patient's ability in carrying out specific tasks that are required to administer eye drops in the correct technique. The older adults' patient's response for this glaucoma medication selfefficacy scale is categorized for self-efficacy items into $(0=$ Does not apply; $1=$ not at all confident; $2=$ somewhat confident, $3=$ very confident). The items for self-efficacy in carrying out specific tasks' subscale were summed and scored from 0 to 42 . Where the Cronbach alpha for the (first eight items) of the subscale was (0.76), with scores ranging from 0-24 and the other (six-items) of the subscale was 0.87 , with scores ranged from 0-18. The higher score indicated high self-efficacy and lower scores indicated low self-efficacy.

(3-III) Outcome expectation subscale - which included 4 items that examine the patient's beliefs and thoughts pre-intervention at baseline data and post-intervention at week 12 which reflecting their behavior change that has a direct impact on their health vision condition when following the health instructions correctly about his antiglaucoma medication. The patient responses for this scale was rated on a 9-point Likert scale, where all response items are summed and ranged from 4-36 and Cronbach's alpha was (0.83). The score for the items was categorized into $(1=$ not at all, $2=$ somewhat, and $3=$ extremely). The higher score indicated positive outcome expectation i.e., the patient who is more active and persistent to accomplish the task and the low score indicated negative outcome expectation i.e., the patient who is less active and not able to persistent to accomplish the task. ${ }^{(22,48)}$

Validity and Reliability: In the current study, these tools were adopted and translated from English to the Arabic language by independent translators for the convenience of its contents and tested for content validity by different experts in the field of community health nursing and geriatric nursing. The required modification was done accordingly. This version was checked by the researchers of the present study to assess the similarity between the original version and the back-translated version to avoid discrepancies. The internal consistency was tested after translation where the values of the Cronbach alpha for medication adherence rate was 0.76 . The self-efficacy in overcoming barriers subscale was 0.83 ; meanwhile, the Cronbach's alpha for the first eight items of the glaucoma medication self-efficacy scale was $(0.75)$, and the other sixitems was (0.80); the glaucoma outcome expectation scale was $(0.82)$.

Pilot Study: The questionnaire was piloted among (15) older adults' patients with glaucoma which represents $10 \%$ of the study sample to assess the clarity and feasibility of the 
Journal of Health, Medicine and Nursing

ISSN 2520-4025 (Online)

Vol.5, Issue 4. No.5, pp 44- 70, 2020

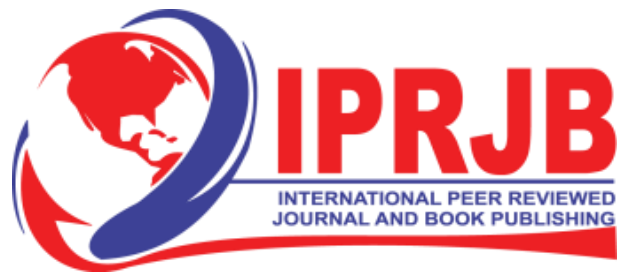

WWW.iprjb.org

Table 1: Risk Factors of Adherence to Medications among Older Adults Participants with Glaucoma

\begin{tabular}{|c|c|c|c|c|c|c|c|}
\hline \multirow{3}{*}{ Variables } & \multicolumn{4}{|c|}{ Studied Sample with Glaucoma $(n=284)$} & \multirow{4}{*}{$\begin{array}{l}\text { Odds } \\
\text { Ratio }\end{array}$} & \multirow{4}{*}{$\begin{array}{c}95 \% \\
\text { Confidenc } \\
\text { e Interval }\end{array}$} & \multirow{4}{*}{$\begin{array}{c}\text { P- } \\
\text { value }\end{array}$} \\
\hline & \multicolumn{2}{|c|}{ Non-Adherent } & \multicolumn{2}{|c|}{ Adherent } & & & \\
\hline & Frequency & Percent & Frequency & Percent & & & \\
\hline & 152 & $53.5 \%$ & 132 & $46.5 \%$ & & & \\
\hline \multicolumn{8}{|l|}{ Age (Year) } \\
\hline Young-old $(60-$ years $)$ & 28 & $18.4 \%$ & 125 & $94.7 \%$ & \multirow{2}{*}{10.9} & \multirow{2}{*}{$6.8-16.32$} & \multirow{2}{*}{$0.000 * *$} \\
\hline Old-old (74-years) & 124 & $81.6 \%$ & 7 & $5.3 \%$ & & & \\
\hline \multicolumn{8}{|l|}{ Gender } \\
\hline Female & 43 & $28.3 \%$ & 111 & $84.1 \%$ & \multirow{2}{*}{1.64} & \multirow{2}{*}{$1.75-3.5$} & \multirow{2}{*}{$0.02 *$} \\
\hline Male & 109 & $71.7 \%$ & 21 & $15.9 \%$ & & & \\
\hline \multicolumn{8}{|l|}{ Marital status } \\
\hline Married & 12 & $7.9 \%$ & 110 & $83.3 \%$ & \multirow{2}{*}{0.55} & \multirow{2}{*}{$0.37-2.45$} & \multirow{2}{*}{0.78} \\
\hline Widowed & 140 & $92.1 \%$ & 22 & $16.7 \%$ & & & \\
\hline \multicolumn{8}{|l|}{ Level of education } \\
\hline Not educated & 136 & $89.5 \%$ & 20 & $15.2 \%$ & \multirow{2}{*}{1.65} & \multirow{2}{*}{$1.02-3.24$} & \multirow{2}{*}{$0.04 *$} \\
\hline Educated & 16 & $10.5 \%$ & 112 & $84.8 \%$ & & & \\
\hline \multicolumn{8}{|l|}{ Living arrangement } \\
\hline Live alone & 104 & $68.4 \%$ & 30 & $22.7 \%$ & \multirow{2}{*}{1.78} & \multirow{2}{*}{$1.06-3.03$} & \multirow{2}{*}{$0.03 *$} \\
\hline Live with family & 48 & $31.6 \%$ & 102 & $77.3 \%$ & & & \\
\hline \multicolumn{8}{|c|}{ Family history of glaucoma } \\
\hline Yes & 70 & $46.1 \%$ & 72 & $54.5 \%$ & 1.40 & $088-215$ & 008 \\
\hline No & 82 & $53.9 \%$ & 60 & $45.5 \%$ & 1.40 & $0.00 .-2.15$ & 0.00 \\
\hline No. of chronic illness & & & & & & & \\
\hline $1-2$ & 11 & $7.2 \%$ & 114 & $86.4 \%$ & & & \\
\hline More than 2 & 141 & $92.8 \%$ & 18 & $13.6 \%$ & 12.6 & $8.2-18.4$ & $0.000^{* * *}$ \\
\hline Duration of glaucoma & (Year) & & & & & & \\
\hline$>5$ & 87 & $57.2 \%$ & 65 & $49.2 \%$ & & & \\
\hline$<5$ & 65 & $42.8 \%$ & 67 & $50.8 \%$ & 0.60 & $0.33-2.10$ & 0.84 \\
\hline Which eye affected by & glaucoma & & & & & & \\
\hline Unilateral & 92 & $60.5 \%$ & 73 & $55.3 \%$ & 124 & 073236 & 023 \\
\hline Bilateral & 60 & $39.5 \%$ & 59 & $44.7 \%$ & 1.34 & $0.13-2.50$ & 0.23 \\
\hline Number of glaucoma & nedication a & e used & & & & & \\
\hline 2-3 medications & 15 & $9.9 \%$ & 112 & $84.8 \%$ & & & \\
\hline $\begin{array}{l}\text { More than three } \\
\text { Medications }\end{array}$ & 137 & $90.1 \%$ & 20 & $15.2 \%$ & 13.2 & $7.4-19.8$ & $0.000 * *$ \\
\hline
\end{tabular}

Table (1) revealed that the highest prevalent risk factors of non-adherence with glaucoma medication among older adults are old-old age group compared with participants of the youngold group ( $\mathrm{OR}=10.9 ; 95 \% \mathrm{CI}$ 6.8-16.32, $\mathrm{P}=0.000$ ), presence of multiple chronic illnesses (more than three) than older adults who had one or two multiple chronic illnesses (OR=12.6; 95\% CI 8.2-18.4, $\mathrm{P}=0.000$ ), older adults who received polypharmacy for managing their illness than those who received only one or two medication $(\mathrm{OR}=13.2 ; 95 \%$ CI $7.7-19.8, \mathrm{P}=0.000)$ respectively. Factors associated with adherence to glaucoma's medication, a significant 
Journal of Health, Medicine and Nursing

ISSN 2520-4025 (Online)

Vol.5, Issue 4. No.5, pp 44- 70, 2020

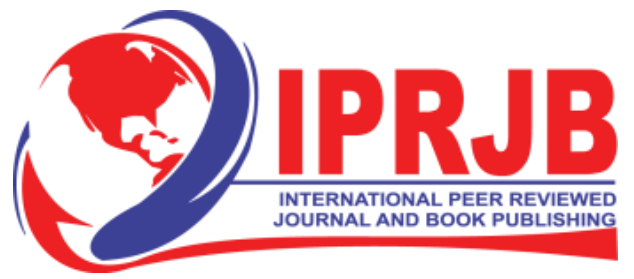

WWW.iprjb.org

statistical difference was found among males and females participant in relation to gender, $(\mathrm{OR}=1.64,95 \% \mathrm{CI} 1.75-3.5, \mathrm{P}=0.02)$, level of education, $(\mathrm{OR}=1.65,95 \% \mathrm{CI} 1.02-3.24, \mathrm{P}=0.04)$; and living arrangement respectively: $(\mathrm{OR}=1.78,95 \% \mathrm{CI} 1.06-3.03, \mathrm{P}=0.03)$ respectively.

Regarding marital status, family history of glaucoma, duration of glaucoma, and which eye is affected were not significant risk factors for adherence to medication among older adults' participants who are suffering from glaucoma. The results displayed that there is no significant differences between married and unmarried study participants for adherence to medication $(\mathrm{OR}=0.55,95 \%$ CI $0.37-2.45, \mathrm{P}=0.78)$. Similarly, there are no significant differences between study participants who have a family history of glaucoma and who did not family history of glaucoma for adherence to medication $(\mathrm{OR}=1.40$, 95\% CI 0.88-2.15, $\mathrm{P}=0.08)$. In addition, the results presented that there is no significant differ among long term and short term duration of glaucoma in the study participants for adherence to medication ( $\mathrm{OR}=0.60,95 \%$ CI 0.33 $2.10, \mathrm{P}=0.84)$; also in comparison to which eye is affected by glaucoma among the study participants, the results indicated that there is no significant difference among unilateral and bilateral glaucoma for adherence to medication $(\mathrm{OR}=1.34,95 \% \mathrm{CI} 0.73-2.36, \mathrm{P}=0.23)$. 
Journal of Health, Medicine and Nursing

ISSN 2520-4025 (Online)

Vol.5, Issue 4. No.5, pp 44- 70, 2020

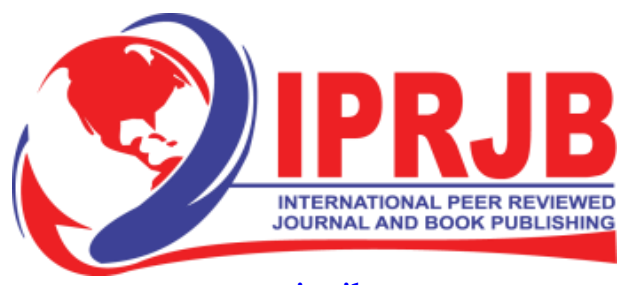

WWW.iprjb.org

Table 2: Bio-Socio-demographic Characteristics of the Non-adherence to Medication among Studied Groups

\begin{tabular}{|c|c|c|c|c|}
\hline \multirow{3}{*}{ Variables } & \multicolumn{4}{|c|}{$\begin{array}{l}\text { Non-adherence to Medication Groups } \\
\qquad(\mathrm{n}=152)\end{array}$} \\
\hline & \multicolumn{2}{|c|}{ Study Group } & \multicolumn{2}{|c|}{ Control Group } \\
\hline & Frequency & Percent & Frequency & Percent \\
\hline & 76 & $100 \%$ & 76 & $100 \%$ \\
\hline \multicolumn{5}{|l|}{ Age (Year) } \\
\hline Young-old $(60-$ years $)$ & 20 & $26.3 \%$ & 5 & $6.6 \%$ \\
\hline Old-old (74-years) & 56 & $73.7 \%$ & 71 & $93.4 \%$ \\
\hline Mean \pm SD & \multicolumn{2}{|c|}{$74.93 \pm 5.7$} & \multicolumn{2}{|c|}{$74.78 \pm 2.70$} \\
\hline \multicolumn{5}{|l|}{ Gender } \\
\hline Female & 30 & $39.5 \%$ & 15 & $19.7 \%$ \\
\hline Male & 46 & $60.5 \%$ & 61 & $80.3 \%$ \\
\hline \multicolumn{5}{|l|}{ Marital status } \\
\hline Married & 17 & $22.4 \%$ & 12 & $15.8 \%$ \\
\hline Widowed & 59 & $77.6 \%$ & 64 & $84.2 \%$ \\
\hline \multicolumn{5}{|l|}{ Level of education } \\
\hline Not educated & 67 & $88.2 \%$ & 59 & $77.6 \%$ \\
\hline Educated & 9 & $11.8 \%$ & 17 & $22.4 \%$ \\
\hline \multicolumn{5}{|l|}{ Living arrangement } \\
\hline Live alone & 59 & $77.6 \%$ & 63 & $82.9 \%$ \\
\hline Live with family & 17 & $22.4 \%$ & 13 & $17.1 \%$ \\
\hline \multicolumn{5}{|l|}{ Family History of glaucoma } \\
\hline Yes & 57 & $75.0 \%$ & 53 & $69.7 \%$ \\
\hline No & 19 & $25.0 \%$ & 23 & $30.3 \%$ \\
\hline \multicolumn{5}{|l|}{ No. of chronic illness } \\
\hline $1-2$ & 8 & $10.5 \%$ & 11 & $14.5 \%$ \\
\hline More than 2 & 68 & $89.5 \%$ & 65 & $85.5 \%$ \\
\hline \multicolumn{5}{|l|}{ Duration of glaucoma (Year) } \\
\hline$>5$ & 39 & $51.3 \%$ & 41 & $53.9 \%$ \\
\hline$<5$ & 37 & $48.7 \%$ & 35 & $46.1 \%$ \\
\hline Mean \pm SD & \multicolumn{2}{|c|}{$3.80 \pm .67$} & \multicolumn{2}{|c|}{$3.67+.59$} \\
\hline \multicolumn{5}{|c|}{ Which eye affected by glaucoma } \\
\hline Unilateral & 60 & $78.9 \%$ & 66 & $86.8 \%$ \\
\hline Bilateral & 16 & $21.1 \%$ & 10 & $13.2 \%$ \\
\hline \multicolumn{5}{|c|}{ Number of glaucoma medication are used } \\
\hline 2-3 medications & 12 & $15.7 \%$ & 7 & $9.2 \%$ \\
\hline More than three Medications & 64 & $84.3 \%$ & 69 & $90.8 \%$ \\
\hline Mean \pm SD & \multicolumn{2}{|c|}{$4.75 \pm .43$} & \multicolumn{2}{|c|}{$4.64 \pm .48$} \\
\hline
\end{tabular}

Table (2) presented bio-sociodemographic data of the studied groups of the elderly participants who have glaucoma and non-adhering to medication. In this study, the total screened elderly participants with glaucoma (284) had a high percent of non-adherent to medication (53.5\%). This non-adherent group sample (152) was divided equally into two groups (76) patients for the study group and (76) for the control group. As inferred from the table, the age of the study sample who are non-adherence to medication was ranged between 60-78 years old and the mean of age and 
Journal of Health, Medicine and Nursing

ISSN 2520-4025 (Online)

Vol.5, Issue 4. No.5, pp 44- 70, 2020

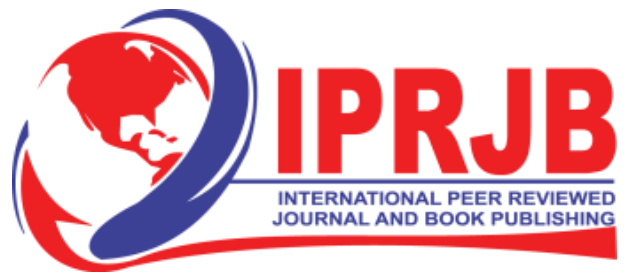

WWW.iprjb.org

SD for the study group was 74.93 \pm 5.7 , while the mean age for the control group was74.78 \pm 2.70 . In addition, the higher percent of non-adherence to medication $73.7 \%$ \& $93.4 \%$ was related to the "old-old group" among study and control groups compared to the young-old group. Regarding gender, non-adherence to medication was higher $60.5 \%$ \& $80.3 \%$ among males compared to males in both study and control groups. Furthermore, non-adherence to medication was higher $77.6 \%$ \& $84.2 \%$ among widowed compared to married in both studied groups. For the level of education, the results showed that the higher percentage of non-adherence to medication among non-educated elderly participants in both study and control groups was $88.2 \%$ \& $77.6 \%$ respectively compared to educated participants. In relation to the living arrangements, the results exhibited that a higher percent of non-adherence to medication among elderly participants who are living alone in both study and control groups $77.6 \%$ \& $82.9 \%$ respectively compared to the study participants who are living with their families.

Meanwhile, the result showed that the family history of glaucoma among both study and control groups had close percent to non-adherent to medication $(75.0 \%$ \& 69.7\%) respectively. In relation to the elderly participants who had multiple-chronic illnesses (more than three diseases) are the one who had a higher percent of non-adherence to medication in both study and control groups $(89.5 \%$ \& $85.5 \%)$ respectively compared to study participants who have one or two chronic illnesses. Regarding the duration of glaucoma and which eye is affected, the results displayed that the percent of non-adherence to medication is almost closed between the entire study participants who had glaucoma less or more than five years as well as if they have bilateral or bilateral glaucoma. In addition, the result revealed the study participants in both study and the control group who had polypharmacy are the ones who had a higher percent of non-adherence to medication $(84.3 \%$ \& $90.8 \%)$ respectively compared to study participants who have one or two medications.

Table 3: Total Mean Score of Self-Efficacy in Overcoming Barriers that Might Interfere with Glaucoma Medications Adherence among Study and Control Groups Pre and Post Program Intervention

\begin{tabular}{|c|c|c|c|c|c|c|}
\hline \multirow[t]{2}{*}{ Study } & \multirow[t]{2}{*}{ Mean \pm SD } & \multicolumn{2}{|c|}{$\begin{array}{c}95 \% \text { Confidence Interval } \\
\text { of the Difference }\end{array}$} & \multirow[t]{2}{*}{$\mathbf{t}$} & \multirow[t]{2}{*}{ df } & \multirow[t]{2}{*}{$\begin{array}{c}\text { Sig. } \\
\text { (2-tailed) }\end{array}$} \\
\hline & & Lower & Upper & & & \\
\hline $\begin{array}{l}\text { Baseline Data (Pre-Intervention) } \\
\text { Study Group } \\
\text { Control Group }\end{array}$ & $-.06579 \pm .52499$ & -.18575 & .05418 & -1.092 & 75 & .278 \\
\hline $\begin{array}{l}4 \text { Weeks (Post-intervention) } \\
\text { Study Group } \\
\text { Control Group }\end{array}$ & $.01316 \pm .64277$ & -.13372 & .16004 & 7.178 & 75 & $.059 *$ \\
\hline $\begin{array}{l}8 \text { Weeks (Post-intervention) } \\
\text { Study Group } \\
\text { Control Group }\end{array}$ & $.96053 \pm .62055$ & .81872 & 1.10233 & 13.494 & 75 & $.000 * *$ \\
\hline $\begin{array}{l}\text { 12 Weeks (Post-intervention) } \\
\text { Study Group } \\
\text { Control Group }\end{array}$ & $1.06579 \pm .61829$ & 92450 & 1.20707 & 15.028 & 75 & $.000 * *$ \\
\hline
\end{tabular}

$* \mathrm{P}<0.05$ level of significance

$* * \mathrm{P}<0.001$ level of significance

As shown in Table (3), the result supported the first hypothesis which states, "The study group of the elderly patients who received the intervention program of glaucoma medication management 
Journal of Health, Medicine and Nursing

ISSN 2520-4025 (Online)

Vol.5, Issue 4. No.5, pp 44- 70, 2020

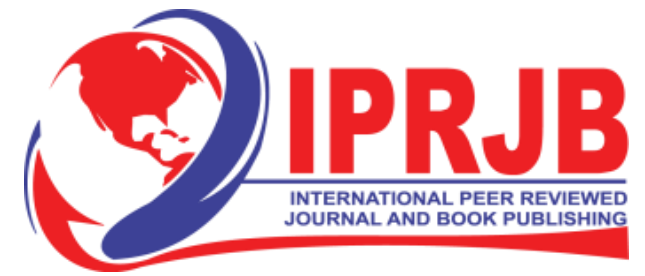

WWW.iprjb.org

may exhibit a significant improvement in their self-efficacy in overcoming medication adherence barriers compared to the control group". In this table, the results revealed that there were no significant differences between the mean score of self-efficacy in overcoming medication adherence barriers among study and control groups pre-intervention program as a baseline data at $\mathrm{T} 1=$ first week $(\mathrm{P}=0.278)$. Meanwhile, there was a significant difference between the mean score of self-efficacy in overcoming medication adherence barriers among study group after each educational sessions at a variety of time "T2=fourth week, T3= eighth week, T4= twelfth week" $(\mathrm{P}=0.059 ; \mathrm{P}=0.000 ; \& \mathrm{P}=0.000)$ respectively.

Table 4: Total Mean Score of Self-Efficacy in Carrying Out Specific Task for Glaucoma Medications

Correctly among Study and Control Groups Pre and Post Program Intervention

\begin{tabular}{|c|c|c|c|c|c|c|}
\hline \multirow[t]{2}{*}{ Study Period } & \multirow[t]{2}{*}{ Mean \pm SD } & \multicolumn{2}{|c|}{$\begin{array}{c}\text { 95\% Confidence Interval } \\
\text { of the Difference }\end{array}$} & \multirow[t]{2}{*}{ t } & \multirow[t]{2}{*}{ df } & \multirow{2}{*}{$\begin{array}{c}\text { Sig. } \\
\text { (2-tailed) }\end{array}$} \\
\hline & & Lower & Upper & & & \\
\hline $\begin{array}{l}\text { Baseline Data (Pre- Intervention) } \\
\text { Study Group } \\
\text { Control Group }\end{array}$ & $.02632 \pm .16114$ & -.01051 & .06314 & 1.424 & 75 & .159 \\
\hline $\begin{array}{l}4^{\text {th }} \text { Weeks (Post-intervention) } \\
\text { Study Group } \\
\text { Control Group }\end{array}$ & $.15789 \pm .40175$ & .06609 & .24970 & 3.426 & 75 & $.001^{* *}$ \\
\hline $\begin{array}{l}\mathbf{8}^{\text {th }} \text { Weeks (Post-intervention) } \\
\text { Study Group } \\
\text { Control Group }\end{array}$ & $1.03947 \pm .52766$ & .91890 & 1.16005 & 17.174 & 75 & $.000 * *$ \\
\hline $\begin{array}{l}\mathbf{1 2}^{\text {th }} \text { Weeks (Post-intervention) } \\
\text { Study Group } \\
\text { Control Group }\end{array}$ & $1.10526 \pm .53114$ & .98389 & 1.22663 & 18.141 & 75 & $.000 * *$ \\
\hline
\end{tabular}

$* \mathrm{P}<0.05$ level of significance

$* * \mathrm{P}<0.001$ level of significance

In Table (4), the results exhibited the second hypothesis that stated, "The study group of the elderly patients who received the intervention program of glaucoma medication management may exhibit a significant improvement in their self-efficacy on the ability in carrying out glaucoma medication correctly compared to the control group". The findings in table (4), presented that there were no significant differences between the mean score of their self-efficacy on the ability to carrying out glaucoma medication correctly among study and control groups in the pre-intervention program at $\mathrm{T} 1 \quad(\mathrm{P}=0.159)$. Meanwhile, after the demonstration and redemonstration of the intervention training program among a study group at a variety of time (T2, T3, T4), the results showed that there is an improvement in their self-efficacy in their ability in carrying out glaucoma medication correctly compared to the control group that is shown by a highly statistically significant differences between total mean scores at $(\mathrm{P}=0.001, \mathrm{P}=0.000 ; \&$ $\mathrm{P}=0.000)$ respectively. 
Journal of Health, Medicine and Nursing

ISSN 2520-4025 (Online)

Vol.5, Issue 4. No.5, pp 44- 70, 2020

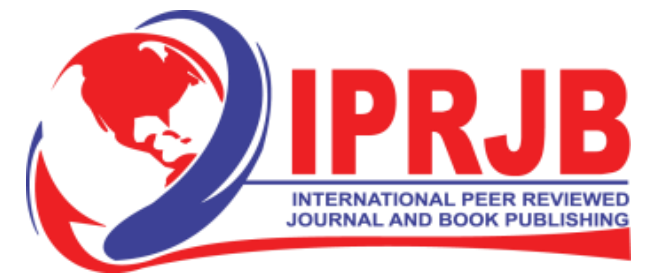

WWW.iprjb.org

Table 5: Total Mean Score of Medication Adherence Behavior Change among Study and Control Groups Pre and Post Program Intervention

\begin{tabular}{|l|c|c|c|c|c|c|}
\hline \multirow{2}{*}{ Study Period } & \multirow{2}{*}{ Mean \pm SD } & \multicolumn{2}{|c|}{$\begin{array}{r}\text { 95\% Confidence Interval } \\
\text { of the Difference }\end{array}$} & \multirow{2}{*}{ t } & df & $\begin{array}{c}\text { Sig. } \\
\text { (2-tailed) }\end{array}$ \\
& & Lower & Upper & & \\
\hline $\begin{array}{l}\text { Baseline Data (Pre- Intervention) } \\
\text { Study Group } \\
\text { Control Group }\end{array}$ & $-.01316 \pm .11471$ & -.03937 & .01305 & -1.000 & 75 & .321 \\
\hline $\begin{array}{l}\text { 4 Weeks (Post-intervention) } \\
\text { Study Group } \\
\text { Control Group }\end{array}$ & $.18421 \pm .39023$ & .09504 & .27338 & 4.115 & 75 & $.002^{* *}$ \\
\hline $\begin{array}{l}\text { 8 Weeks (Post-intervention) } \\
\text { Study Group } \\
\text { Control Group }\end{array}$ & $.47368 \pm .50262$ & .35883 & .58854 & 8.216 & 75 & $.000^{* *}$ \\
\hline $\begin{array}{l}\text { 12 Weeks (Post-intervention) } \\
\text { Study Group } \\
\text { Control Group }\end{array}$ & $.63158 \pm .53770$ & .50871 & .75445 & 10.24 & 75 & $.000^{* *}$ \\
\hline
\end{tabular}

$* \mathrm{P}<0.05$ level of significance

$* * \mathrm{P}<0.001$ level of significance

In Table (5), the results displayed the third hypothesis that stated, "The study group of the elderly patients who received the intervention program of glaucoma medication management may exhibit a significant improvement in their adherence to medication behavior compared to the control group. As illustrated in this table, the findings showed that there were no statistically significant differences between total mean scores of adherence to medication behavior change among study and control groups in the pre-intervention program at $\mathrm{T} 1(\mathrm{P}=0.321)$. Meanwhile, after the demonstration and re-demonstration the intervention program among study group at a variety of times (T2, T3, T4), the results showed that there was a statistically significant difference in their adherence to medication compared to the control group at mean scores $(\mathrm{P}=0.002 ; \mathrm{P}=0.000 ; \& \mathrm{P}=0.000)$ respectively. 
Journal of Health, Medicine and Nursing

ISSN 2520-4025 (Online)

Vol.5, Issue 4. No.5, pp 44- 70, 2020

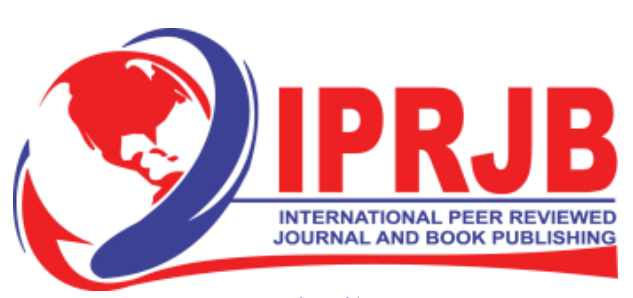

WWw.iprjb.org

Liou,(2015); Pasina et al.,(2014) who specified that approximately 40-72\% of older adults' persons had non-adherence to medications more than the other age groups. ${ }^{(18-20 ; 49,50)}$ However, this the result was inconsistent with Pagès-Puigdemont, Tuneu, Masip, Valls, Puig, \& Mangues, (2019) who reported that about $54.5 \%$ of older adults were fully adhering to the prescribed medications worldwide and the adherence rate is ranged from $47 \%$ to $100 \%$ in several studies. ${ }^{(51)}$ This non-adherence to medication among studied groups may be due to older adult people are likely to have similar barriers and challenges which are always associated with the aging process such as impairment of their functional capacity and cognitive impairment, present of multiple chronic illnesses with poly-medications, and patients' beliefs which result in low self-efficacy to keep continuity and reserve their medications intake to improve their vision health condition and prevent deterioration.

In relation to age group, the result of this study projected that non-adherence to glaucoma medications among the elderly participants have represented a higher percentage among the oldold group 74 years old more than a young-old group who 60 years. This finding was consistent with Mahmoodi, et al.,(2019);Lee et al.,(2018); Ma, et al.,(2015) ; Kharameh , Khoshravesh , Nouri , Abdolmalaki \& Bakhshi,(2018); Sirey, Weinberger , Greenfield, \& Bruce, (2013) reported that the rates of non-adherence to medication is high among older adults over the age of 60 years compared to any other age groups and increased gradually with advanced age where the glaucoma prevalence increases dramatically with age which may result in intensely the elderly population with glaucoma-related visual disability. ${ }^{(18,19,49,52,53)}$ In addition, Al-Mansouri, Kanaan, Gamra, Khandekar, Hashim Al Qahtani, \& Ahmed,(2011) revealed that glaucoma and different visual disabilities among subjected aged 40-49 years were not available as the visual acuity for the blindness and low vision study focused on the subjects 50 years or older. In other words, subjects among the age group of 60 years and older had a significantly higher risk of glaucoma compared with subjects in the 40-59 years age group $(\mathrm{P}=0.00001) .{ }^{(54)}$ This could be explained that older Egyptian's adults may feel that they lived their life till the end and normally this is the aging process's consequences and taking more medications will not make a difference to their quality of life. Also, their non-adherence to medication is positively related to their level of education where most of the studied participants who are not educated; can't follow the written prescription of glaucoma medication administration.

In reference to gender, the finding of this study showed that male older adults' the participant had a higher percent of non-adherence to medication more than females among studied groups. In addition, gender is a high-risk factor of an adherent to medication in this study where the results displayed the difference among males and females $(\mathrm{P}=0.02)$. This result was agreed with Zucker \& Prendergast (2020); Marcos-Marcos, Gasch-Gallén, Mateos, \& ÁlvarezDardet,(2020); Chu,(2014); Soldin and Mattison,(2012); Al-Mansouri, et al.,(2011) who stated that gender-role characters and social stereotypes were described that the effect of medication adherence and it is important to consider the differences in the distribution of medicines, metabolism, efficacy, and side effects of prescribed medicines that have been reported for both gender, with a potential effect on medication adherence. ${ }^{(55-58,54)}$ In addition, Rajpura \& Nayak,(2014); Vaidya, Partha, \& Karmakar, (2012); Emilsson, et al., (2011) who reported that women are more likely to seek preventive care and treatment than men. ${ }^{(59,60,61)}$ According to Holt et al., (2013) study the results shown that sex-related differences in the effects of some medications used by the older population could stem from differences in medication adherence, 
Journal of Health, Medicine and Nursing

ISSN 2520-4025 (Online)

Vol.5, Issue 4. No.5, pp 44- 70, 2020

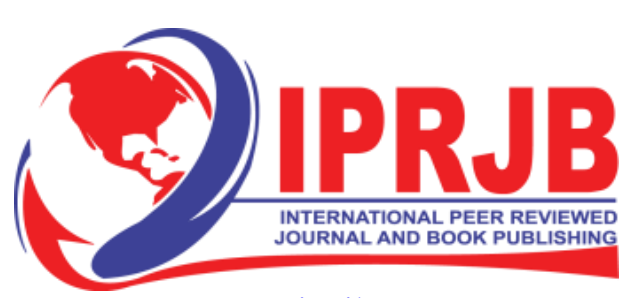

WWW.iprjb.org

for the occasion that the effect anti-hypertension pills could cast on the sexual function of older men may lead to their low or non-adherence compared to the hypertensive older women. ${ }^{(62)}$

In contradictory, the finding in some studies was done by Segarra, Modamio, Fernandez \& Marino, (2017); Manteuffel, Williams, Chen, Verbrugge, Pittman, \& Steinkellner (2014); Holt, et al., (2013) found that gender-based differences in medication adherence is not still conclusive, but it is reported that among women are more used to multiple medications and non-compliance with the recommendations of health care providers which have a direct influence on women's decision to not comply with the prescribed medications compared to the men who had similar conditions of chronic illness. ${ }^{(63,64,62)}$

The results of the current study revealed that marital status was not a significant risk factor for the adherence to medication among older adults' participants who are suffering from glaucoma $(\mathrm{P}=0.78)$. This finding was consistent with $\mathrm{Ma}$, et al., (2015) who reported that medications adherence behaviors of the elderly participants had no relationship with marital status. ${ }^{(49)}$ Conversely, Mahmoodi, et al.,(2019) stated that the married study attendees had significantly better adherence to medication compared with single older adults. ${ }^{(18)}$ This could be explained that older adult's married participants are struggling to accomplish different roles at the same time; self-management of their health problems, continue to work even after the retirement period. Also, considering their low socioeconomic status they may take less medication in order to avoid its cost burdens. Also, limited understanding of the disease process and treatment regimen, difficult access to medication, and lack of communication with the pharmacist may all contribute to medication non-adherence among married older adults.

Regarding educational level, the result of this study showed that the education level of the elderly participants was a significant risk factor for the adherence to medication among older adults' participants who are suffering from glaucoma $(\mathrm{P}=0.04)$. This result comes in agreement with Mayo-Gamble \& Mouton, (2018); Jin, Kim, \& Rhie,(2016); Wang, Lau, Loo, Chow, \& Thompson, (2014) reported that older adults who have less health literacy are more likely to take less medication than those who are instructed. ${ }^{(65-67)}$ In addition, Jin, et al., (2016); Wang, et al., (2014) depicted that the education level of elderly people is strongly associated with their medication adherence and the elderly people who had a high level of education is more adherence to their medication. ${ }^{(66,67)}$ On the other hands, Vélez-Vélez, and Bosch,(2016); Woith, and Rappleyea,(2016) shown that the elderly patients who are understanding of their illness can enhance their ability to manage the disease and subsequently follow the medication regimen, because the illness perception or understanding their current disease is one of the important behavioral determinants of medication adherence. ${ }^{(68,69)}$ This result is inconsistent with Ma, et al.,(2015) who mentioned that medications adherence behaviors of the elderly people had no relationship with their educational background. ${ }^{(4)}$

In this study, the results revealed that the living arrangement is a highly significant risk factor of an adherent of medication where the results displayed differ among the elderly who are living alone or with the family ( $\mathrm{P}=0.03)$. This result is consistent with Mahmoodi, et al.,(2019) study which showed that living alone had a significant precipitator of medication adherence compared with the participants who are not living alone. The interpretation of this result may be due to the elderly who have family or children spouse those are the ones providing social and family support to take care of themselves and take medications on time. ${ }^{(18)}$ 
Journal of Health, Medicine and Nursing

ISSN 2520-4025 (Online)

Vol.5, Issue 4. No.5, pp 44- 70, 2020

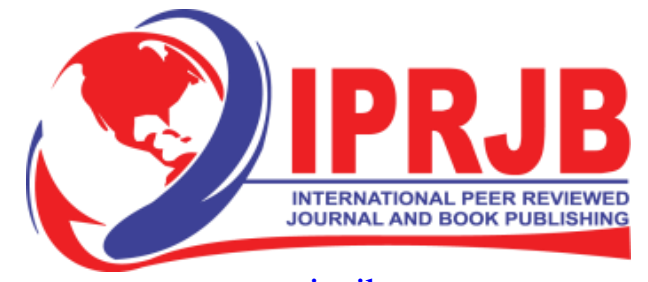

www.iprib.org

barriers to being more effective methods for increasing medication self-efficacy which definitely reflect positively health outcomes on the patients' health condition.

Recommendation: The findings confirm the effectiveness of an intervention program based on self-efficacy theory in terms of improving glaucoma medication adherence among older adults. Glaucoma's medication principles should be discussed at regular intervals based on patients' needs and the barriers, they are facing.

\section{References}

1. Flaxman SR, et al. Global causes of blindness and distance vision impairment 1990-2020: a systematic review and meta-analysis. The Lancet Global Health, 2017 Dec; 5(12):e1221e1234. DOI: 10.1016/S2214-109X (17)30393-5.

2. Tham Y, Li X, Wong TY, Quigley HA, Aung T, Cheng C. Global prevalence of glaucoma and projections of glaucoma burden through 2040: a systematic review and meta-analysis. Ophthalmology, 2015 July; Volume 122, Issue 7, Pages e40-e41.

3. World Health Organization. Situation Analysis of VISION 2020 in the WHO South-East Asia Region. 2012.

4. International Agency for the Prevention of Blindness (IAPB): Annual Report 2019. https://www.iapb.org/wp-content/uploads/2019_IAPB_Annual_Report.pdf.

5. Abu Hussein NB, Eissa IM, Abdel-Kader AA. Analysis of Factors Affecting Patients' Compliance to Topical Antiglaucoma Medications in Egypt as a Developing Country Model. J Ophthalmol., 2015. https://www.ncbi.nlm.nih.gov/pubmed/26167292.

6. Amin AM, Kamel AIM, El-Ashkar MGA. Corneal Topographic changes after sub scleral trabeculectomy. AIMJ 2020 February. doi:10.21608.

7. Khalaf FR, Qayed M, Fahmy HD, Wasfi EI, Mohamed AG. Employees Knowledge about Glaucoma at Assiut University Employees. Assiut Scientific Nursing Journal. 2015 June; 3(5):11-17.

8. Smaje A, Clark MW, Raj R, Orlu M, Davis D, Rawle M. Factors associated with medication adherence in older patients: A systematic review. Aging Med (Milton). 2018 Dec; 1(3): 254266.

9. Facts About Glaucoma". National Eye Institute. Archived from the original on 2016 March 28.

10. Eldaly MA, Salama MM, Abu Eleinen KG, Ghalwash D, Youssef M, El-Shiaty AF. Blindness and Visual Impairment among Egyptian Glaucoma Patients. Journal of Ophthalmology, 2014; Article ID 437548.

11. Vos T. Global, regional, and national incidence, prevalence, and years lived with disability for 310 diseases and injuries, 1990-2015: a systematic analysis for the Global Burden of Disease Study. Lancet 2016; 388: 1545-602.

12. Zhong H, et al. The Prevalence of Glaucoma in Adult Rural Chinese Populations of the Bai Nationality in Dali: The Yunnan Minority Eye Study. Investigative Ophthalmology \& Visual Science, 2012 May; Vol.53, 3221-3225. doi: https://doi.org/10.1167/iovs.11-9306. 
Journal of Health, Medicine and Nursing

ISSN 2520-4025 (Online)

Vol.5, Issue 4. No.5, pp 44- 70, 2020

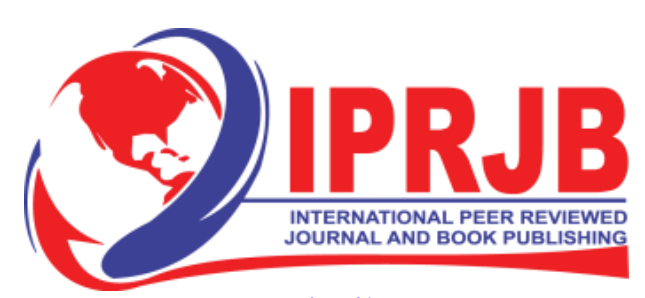

wWw.iprjb.org

42. Patton DE, Ryan C, Hughes CM. Development of a complex community pharmacy intervention package using theory-based behaviour change techniques to improve older adult's medication adherence, BMC Health Services Research, 2020. 10.1186/s12913-020-05282-7.

43. Vrijens B, Antoniou S, Burnier M, de la Sierra A, Volpe M. Current Situation of Medicc Adherence in Hypertension. Front. Pharmacol.,2017, Mi https://doi.org/10.3389/fphar.2017.00100.

44. Kardas P, Lewek P, Matyjaszczyk M . Determinants of patient adherence: a review of systematic reviews. Front Pharmacol. 2013 Jul 25; 4: 91. Doi:10. 3389/ fphar.2013.00091.

45. Navarra AMD, Gwadz MV, Bakken S, Whittemore R, Cleland CM, Melkus GD. Adherence Connection for Counseling, Education, and Support: Research Protocol for a Proof-ofConcept Study. JMIR Res Protoc. 2019 Mar; 8(3): e12543. doi: 10.2196/12543.

46. Lubloy A. Factors affecting the uptake of new medicines: a systematic literature review. BMC Health Services Research. 2014; 14:469

47. Unni EJ , Olson JL, Farris KB. Revision and validation of Medication Adherence Reasons Scale (MAR-Scale). Journal Current Medical Research and Opinion. 2014, 30 , Issue 2.

48. Herndon LW, Brunner TM, Rollins JN. The Glaucoma Research Foundation Patient Survey: patient understanding of glaucoma and its treatment. Am J Ophthalmol., 2006; 141:

49. Ma HJ, Yen M, Chen CH, Liou D (2015). Determinants of the medication adherence behavior among elderly patients with coronary heart diseases. Journal of Nursing Education and Practice, 2015, Vol. 5, No.7

50. Pasina L, Brucato AL, Falcone C, Cucchi E, Bresciani A, Sottocorno M, Taddei G C, Casati M, Franchi C, Djade C D, Nobili A. Medication non-adherence among elderly patients newly discharged and receiving polypharmacy. Drugs Aging. 2014 Apr;31(4):2839. doi: 10.1007/ s40266-014-0163-7.

51. Pagès-Puigdemont N, Tuneu L, Masip M, Valls P, Puig T, Mangues MA. Determinants medication adherence among chronic patients from an urban area: a cross-sectional study.

European Journal of Public Health, Jun 2019; Volume 29, Issue 3, Pages 419-424.

52. Kharameh ZT, Khoshravesh S, Nouri R, Abdolmalaki M, Bakhshi M. Determinants of Medication Adherence Among Iranian Elderly Patients with Chronic Diseases. Jundishapur Journal of Chronic Disease Care in Press (In Press). 2018. DOI: 10.5812/jjcdc.68310.

53. Sirey JA, Weinberger MI, Greenfield A, Bruce ML. Medication beliefs and self-reported adherence among community-dwelling older adults. Clinical Therapeutics, 201326 Jan, 35(2):153-160. DOI: 10.1016/j.clinthera.2013.01.001. 
Journal of Health, Medicine and Nursing

ISSN 2520-4025 (Online)

Vol.5, Issue 4. No.5, pp 44- 70, 2020

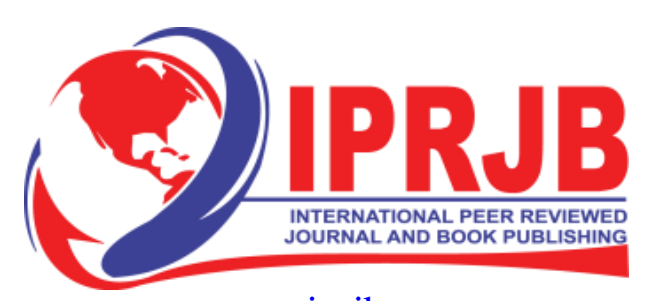

wWw.iprjb.org

67. Wang W, Lau Y, Loo A, Chow A; Thompson DR. Medication adherence and its associated factors among Chinese community-dwelling older adults with hypertension. Heart \& Lung. Jul-Aug 2014;43(4):278-83. DOI: 10.1016/j.hrtlng.

68. Vélez-Vélez E, Bosch RJ. Illness perception, coping and adherence to treatment among patients with chronic kidney disease. J Adv Nurs. 2016;72(4):849-863. doi: 10.1111/jan.

69. Woith WM, Rappleyea ML. Emotional representation of tuberculosis with stigma, treatmen1 delay, and medication adherence in Russia. J Health Psychol. 2016;21(5):770-780. Doi:10.1177/1359105315569620.

70. McClelland JF, Bodle L, Little JA. Investigation of medication adherence and reasons for poor adherence in patients on long-term glaucoma treatment regimes. Patient Prefer Adherence. 2019 Aug 12; 13:431-439. doi: 10.2147/PPA.S176412.

71. McMonnies CW. Glaucoma history and risk factors. J Optom., 2017 April-June; Vol. 10. Issue 2: pages 71-78. DOI: 10.1016/j.optom.

72. Sleath B, et al., The relationship between glaucoma medication adherence, eye drop technique, and visual field defect severity. Ophthalmology. 2011 Dec;118(12):2398-402. doi: 10.1016/j.ophtha.

73. Kleinsinger F. The Unmet Challenge of Medication Nonadherence. Perm J., 2018; 22:18-033 doi: 10.7812/TPP/18-033.

74. Zaugg V; Korb-Savoldelli V; Durieux P; Sabatier B. Providing physicians with feedback on medication adherence for people with chronic diseases taking long-term medication. Cochrane Database Syst Rev. 2018 Jan; (1): CD012042. doi: 10.1002/14651858.CD012042. pub2

75. Sabate E. Adherence to long-term therapies: evidence for action. World Health Organization (WHO). http://www.who.int/ chp/knowledge/publications/adherence report/en/. Accessed 28 June 2016.

76. Gellad WF, Grenard JL, Marcum ZA. A systematic review of barriers to medication adherence in the elderly: looking beyond cost and regimen complexity. Am J Geriatr Pharmacother. 2012; 9:11-23.

77. Godman B, et al. Multiple policies to enhance prescribing efficiency for established medicines in Europe with a particular focus on demand-side measures: findings and future implications. Frontiers in Pharmacology, 2014; 5:106.

78. Duerden M, Avery T, Payne R. Polypharmacy and medicines optimisation: making it safe and sound. The Kings Fund. 2013. http://www. kingsfund.org.uk/publications. Accessed 20 Feb 2016.

79. Ahrari S, Mohammadpour A, Amouzeshi, Z, Agha-Yousefi A. The Relationship between Cognitive Appraisal and Adherence to Medical Regimens in Type 2 Diabetic Patients. J Caring Sci. 2014 Dec; 3(4): 277-285. doi: 10.5681/ics. 
Journal of Health, Medicine and Nursing

ISSN 2520-4025 (Online)

Vol.5, Issue 4. No.5, pp 44- 70, 2020

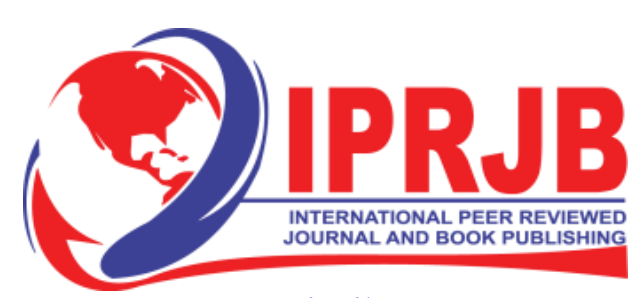

WWw.iprib.org

80. Nieuwlaat $\mathrm{R}$, et al. Interventions for enhancing medication adherence. Cochrane Database Syst Rev. 2014 Nov 20;(11):CD000011. doi: 10. 1002 /14651858.CD000011.pub4.

81. Carpenter D, et al., Communication Predicts Medication Self-Efficacy in Glaucoma Patients. Optometry and Vision Science. July 2016, 93(7):731-737, doi:10.1097/OPX. 000000000000 0856.

82. Slota C, et al., Glaucoma patient expression of medication problems and non-adherence. Optom Vis Sci. 2015 May; 92(5): 537-543.doi: 10.1097/OPX.0000000000000574.

83. Sleath B. et al., Determinants of self-reported barriers to glaucoma medicine administration and adherence: A Multisite Study. Ann Pharmacother. 2014 Jul;48(7):856-862. doi: 10.1177/ 1060028014529413.

84. Carpenter DM, et al., The effect of eye drops technique education in patients with glaucoma. Health Commun. 2016 Aug;31(8):1036-42. doi: 10.1080/10410236.2015.1020263.

85. Michie S, Atkins L, West R. The behaviour change wheel: a guide to designing interventions. 2015; London: Silverback Publishing

86. Lampert A, Bruckner T, Haefeli WE, Seidling HM. Improving eye-drop administration skills of patients - A multicenter parallel-group cluster-randomized controlled trial. PLoS One, 2019; 14(2): e0212007. doi: 10.1371/journal.pone.0212007

87. Morgan, EE; Woods SP; Iudicello JE; Grant I; Villalobos J. Poor Self-efficacy for Healthcare Provider Interactions Among Individuals with HIV-Associated Neurocognitive Disorders. Journal of Clinical Psychology in Medical Settings, 2019, volume 26, pages13-24.

88. Gross IM, Hosek S, Richards MH, Fernandez MI. Predictors and profiles of antiretroviral therapy adherence among African American adolescents and young adult males living with HIV. AIDS Patient Care STDS. 2016 Jul;30(7):324-38. doi: 10.1089/apc.

89. Richard L, Street, Jr. How clinician-patient communication contributes to health Improvement: Modeling pathways from talk to outcome. Patient Education and Counseling, September 2013; Volume 92, Issue 3, Pages 286-291.

90. Centers for Disease Control and Prevention. Estimated HIV incidence and prevalence in the in the United States, 2010-2015-HIV Surveillance Supplemental Report. Mar,2018-07-31. report-vol- 23-1.

91. Kelly M.; McCarthy S; Sahm LJ. Knowledge, attitudes and beliefs of patients and careers regarding medication adherence: a review of qualitative literature. European Journal of Clinical Pharmacology. 2014, volume 70, pages1423-1431. 